\title{
trachealess encodes a bHLH-PAS protein that is an inducer of tracheal cell fates in Drosophila
}

\author{
Ronit Wilk, Isabella Weizman, and Ben-Zion Shilo' \\ Department of Molecular Genetics, Weizmann Institute of Science, Rehovot 76100, Israel
}

The embryonic tracheal system in Drosophila develops from placodes of precursor cells on the ectoderm. A transcription factor of the basic helix-loop-helix (bHLH)-PAS family, which is expressed in the nuclei of the tracheal cells throughout development, was identified. The protein shows the highest degree of homology to the Single-minded (Sim) protein. The transcript represents the previously identified trachealess (trh) locus, essential for tracheal development. Ectopic expression of $t r h$ leads to generation of extra tracheal pits and branches and to the expression of tracheal markers by patches of ectodermal cells. The expression of trh is consistent with a biphasic mode of transcriptional regulation. Expression is first induced by exogenous cues and is subsequently autoregulated. trh is also expressed and required in the posterior spiracles and the salivary gland ducts. The role of Trachealess in the formation of several tubular tissues in the embryo suggests that it may induce a general fate of branched tubular structures of epithelial origin.

[Key Words: Drosophila; embryogenesis; trachea; bHLH; PAS; Trachealess]

Received August 31, 1995; revised version accepted October 26, 1995.

The establishment of organs during development is achieved in many instances through the induction of master regulator genes. Restricted expression of such a gene, guided by external cues, is sufficient to induce the differentiation of the tissue. This is accomplished by the potency of the gene to induce expression of tissue-specific target genes and maintain its own transcription.

Implicit in the induction of transcription by a master regulator is its activity as a transcription factor. Several such proteins have been described. Proteins of the basic helix-loop-helix (bHLH) family were implicated in the induction of tissue identity: The vertebrate MyoD can induce muscle differentiation when expressed in cultured fibroblast cells (Lassar et al. 1986; Davis et al. 1987; Tapscott et al. 1988). In Drosophila, genes of the achaete-scute complex were shown to be necessary and sufficient for the specification of neuroblasts and precursors of several external sense organs (for review, see Skeath and Carroll 1994). Similarly, the atonal gene, encoding another bHLH protein, induces the chordotonal organ and R8 photoreceptor cell fates (Jarman et al. 1993, 1994). Finally, the Single-minded (Sim) protein is necessary and sufficient for the induction of midline cell fates in the embryonic central nervous system. Sim contains a bHLH domain, as well as a domain termed PAS (on the basis of its original identification in the Per, Arnt, and Sim proteins) (Nambu et al. 1991). Transcription factors

\footnotetext{
${ }^{1}$ Corresponding author.
}

of other types can also function as primary switches. For example, the Drosophila Eyeless protein, containing both homeo and Pax domains, is essential for eye development and was shown to induce the formation of eyes at ectopic locations (Halder et al. 1995).

During the early sto jes of embryonic development in Drosophila, the fates of the ectodermal cells are specified by the combined action of maternal and zygotic genes (for review, see St Johnston and Nüsslein-Volhard 1992). Following determination of cell fates along both anterior-posterior and dorsoventral axes, orthogonal intersections define distinct clusters of cells within each segment. These subsets generate the founding cells for tissues that will invaginate or delaminate from the ectoderm, such as the midline cells or neuronal cell clusters of the central and peripheral nervous system. The embryonic tracheal system in Drosophila is an epithelial tubular network that is also established from defined sets of ectodermal precursor cells (for review, see Manning and Krasnow 1993). At stage 10 of embryonic development, lateral ectodermal clusters of cells on both sides of the 10 posterior parasegments (T2-A8) assume a tracheal placode fate. They undergo two more rounds of cell division to generate $\sim 80$ cells in each placode. At stage 11 each cluster of cells invaginates to form the tracheal pits. The subsequent formation of the tracheal tree occurs without any further cell division. The cells of the tracheal pits first carry out a stereotypic migration pattern. They then fuse with other tracheal cells from the adjacent segments to form a continuous tubular net- 
work. Finally, terminal tracheal cells send long extensions toward the target cells, forming blind-ended tubes that are connected to the main tracheal network.

This work describes the mechanism for the induction of primary tracheal cell fates within the embryonic ectoderm. The trachealess (trh) gene, encoding a bHLHPAS protein, is specifically expressed in the cells of the tracheal placodes and continues to be expressed in all tracheal cells throughout embryonic and larval development. It is both necessary and sufficient for the induction of tracheal cell fates: Tracheal placodes are not formed in the absence of a functional protein, whereas ectopic expression of the gene generates extra tracheal pits and induces the expression of tracheal markers by patches of ectodermal cells. Expression of trh is initially triggered by cues from the anterior-posterior and dorsoventral axes and later becomes dependent on Trachealess itself.

\section{Results}

\section{A new $b H L H-P A S$ protein is identified}

by a tracheal-specific enhancer trap line

The homozygous viable enhancer trap line 1-eve-1 is specifically expressed in the tracheal system (Fig. 1; Perrimon et al. 1991). Expression is first detected in the tracheal placodes on the ectoderm at stage 10 (stages according to Campos-Ortega and Hartenstein 1985) (Fig. 1A). It is maintained in all tracheal cells throughout embryogenesis and the larval phases (Fig. 1B). 1-eve-1 is also expressed in the salivary gland duct cells that connect the salivary glands to the atrium of the foregut (data not shown).

Genomic sequences flanking the 1-eve-1 $\mathrm{P}$ element insertion were cloned (see Materials and methods). A map of the 1-eve-1 genomic region is shown in Figure 2A. These genomic clones were used as probes for in situ hybridization to embryos. A 7-kb fragment recognized a transcript expressed in a pattern identical to the original 1-eve-1 line. This fragment was then used to obtain clones from a 9- to 12 -hr embryonic cDNA library. Sequencing of the longest cDNA $(4.2 \mathrm{~kb})$, revealed a single long open reading frame, flanked by long $5^{\prime}$ - and $3^{\prime}$-noncoding sequences. The transcript encodes a protein of 949 amino acids, beginning at the putative initiator methionine at base 680 (according to Kozak 1987). This transcript corresponds to the trh locus (see below).

Conceptual translation of the trh cDNA reading frame reveals several hallmarks of a transcription factor. The encoded protein contains bHLH, PAS, and transcription activation domains and is shown schematically in Figure 2B. The protein displays the highest degree of homology to the Sim protein (Crews et al. 1988; Nambu et al. 1991) (Fig. 2C). Although the amino-terminal 78 residues of the protein are unique, they are followed by a basic region (9/12 residues identical to Sim), an HLH domain (33/40 identical residues), a PAS domain $(67 \%$ and $43 \%$ identity for PAS A and PAS B, respectively), a nuclear localization signal, and a transcription activation domain rich in proline, glutamine, and serine residues.
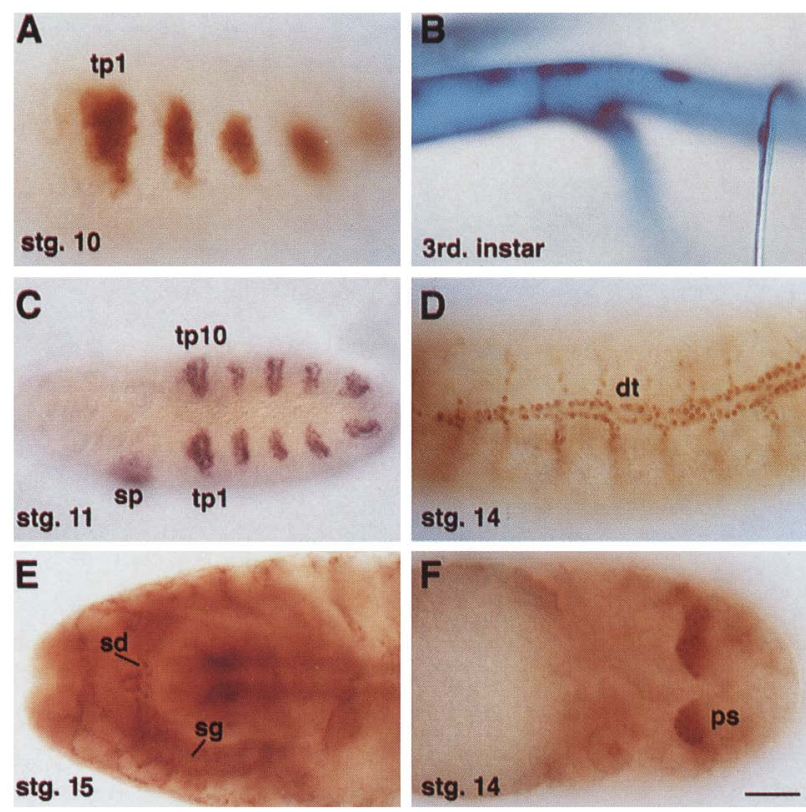

Figure 1. Expression of the l-eve-l enhancer trap and trh during development. Expression of the l-eve-1 enhancer trap was monitored by anti- $\beta G a l|A|$ or $\mathrm{X}$-gal staining $(B \mid$. Stages are shown. (tp)-Tracheal placode. $(C)$ Expression of the trh RNA detected by whole-mount in situ hybridization to the cDNA probe. At stage 11, expression in the tracheal pits $|t p|$ and salivary placode $(\mathrm{sp})$ is detected. Similar results were obtained with Trh antibody staining (data not shown). $(D)$ Trh antibody staining of a stage 14 embryo shows nuclear staining of all tracheal cells. (dt) Dorsal trunk. $(E)$ In stage 15 embryos, the protein is also detected in the salivary duct nuclei (sd). Weak staining is also seen in the salivary glands $(\mathrm{sg})$. $(F)$ In a stage 14 embryo, staining is also detected in the nuclei of the posterior spiracles (ps). Anterior is to the left. Scale bar, $50 \mu \mathrm{m}(C) ; 30 \mu \mathrm{m}\{A, B, D-$ F).

The arrangement of exons within the gene was determined for the available genomic fragments. Four $5^{\prime}$ exons were identified and mapped (Fig. 2A). It is interesting to note that each exon contains a discrete domain of the protein: The first exon encodes the unique amino-terminal sequence, the second contains the bHLH region, and the fourth exon the PAS A domain. Structural analysis of several cDNA clones revealed two instances of alternative splicing in the region between the PAS A and B domains. In one case, the last 6 amino acids encoded by the fourth exon were spliced out, whereas in the second case, an asparagine-rich 29-amino acid stretch in the spacer between the PAS domains was removed (E. Zeltser and B. Shilo, unpubl.).

\section{trh expression pattern}

The expression pattern of the trh transcript and protein was studied. A probe prepared from the cDNA detects expression initially in the tracheal placodes and tracheal pits, as well as in the salivary placodes (in the ventral ectodermal cells of the labial segment) (Fig. 1C). Later 
A
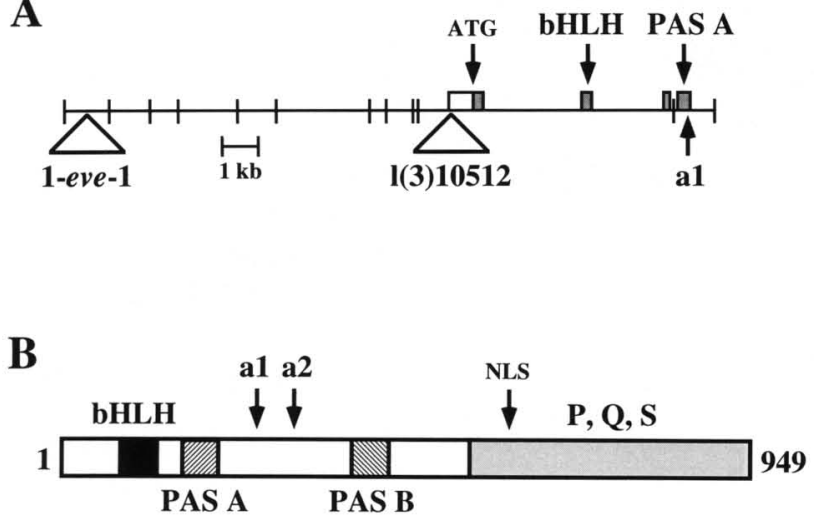

C

1 MDYAGYQRQPTPGHPGSHMATMGSLGMPAVPFTHSWMVPTDLCAMPPYN 50

51 KMTGHQQPPGAGMHAQQQALEPGILELRKEKSRDAARSRRGKENYEFYEL 100 \ $.||||:||||||:|||||:| \mid$ HLH MKEKSKNAARTRREKENTEFCEL 23

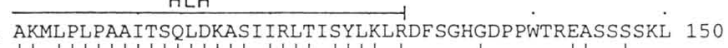

AKLLPLPAAITSQLDKASVIRLTTSYLKMRQVFPDGLG . . . EAWGS . . 66

151 KSAAIRRSPAVDLFEQHQGTHILOSLDGFALAVAADGRFLYISETVSIYL 200 67 .SPAMQRGATIKEL.... GSHLLQTLDGF IFVVAPDGKIMYISETASVHL 11

201 GLSQVEMTGSSIFDYIHQADHSEIADQLGLSLTSGGGGGGGSSSSGGGGG 250 112 GLSQVELTGNSIFEYIHNYDQDEMNAILSLHPHINQHPLAQTHTPIGSPN 161 251 GAGGGMASPTSGASDDGSGTHGTNNPDVAASMTQASTSGYKGYDRSECVR 300 162 GV $\ldots \ldots$ QHPSAYDHDRGSHTI $\ldots \ldots \ldots \ldots \ldots \ldots \ldots$ EIEKTEFLR 187 301 MKSTLTKRGCHEKSSGYRASDATSNCNNGNNASNNAKNVKNPGSNYSVVL 350

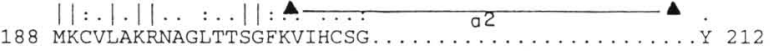
351 LLCKLRPQYTFSHSRKSQPPLLGMVALAIALPPPSVHEIRLECDMFVTRV 400 213 LKARIYPD. .RGDGQGSLIQNLGLVAVGHSLPSAITEIKLHQNMFMFRA 260 401 NFDLRVAHCEPRVSDLLDYSPEDLVNKSLYSLCHAEDANRLRKSHSDLIE 450 $:|::: \quad::|||:|:| .|:||::| .|| \ldots|| .|\quad:||| \mid$ 261 KLDMKLIFFDARVSQLTGYEPQDLIEKTLYQYIHAADIMAMRCSHQILLY 310 451 KGQVLTGYYRLMNKSGGYTWLQTCATVVCSTKNADEQNIICVNYVISNRE 500 ||||||||$::|:|||:|:| .:||:|\ldots: \ldots|||:|||||:|:||$ 311 KGQVTTKYYRFLTKGGGWVWVQSYATLVHNSRSSREVFIVSVNYVLSERE 360 501 NENMILDCCQLEPSPDSIKHEEGLGNDKSSGSPGGDASGEGNSHLSAGDM 550

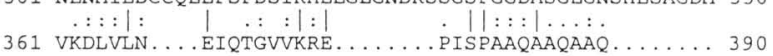
551 KLNSPKTDSEGHSHRGRGRSAAASHGSSMNSLTMIKDSPTPLGVEIDSGV 600 601 LPTTVATPVPAATPPVQSTKRKRKTKASQHAED. QGQEQVISEQPLPKLP 649

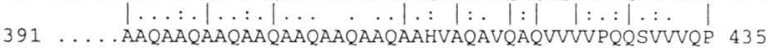
650 TMEQRDQQPRSRLPSIVDEQPSSAADSAVKDLEQAMSKHLPSPATVVSVP 699 436 QCAGATGQP. . . . . . . VGPGTPVSLALSASPKLDPYFEPELPLQPAVTPVP 479 700 PPNTDFSADSLLKQQQQQQQLDPNEKSSTIQWIGTPYQQPPAPMPATALL 749

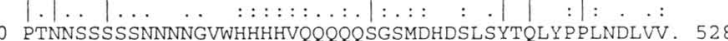
750 RQLYANRESVIRATARQTPTGVGPGVFYGDQQTGPLPTPPGSESSYENQY 799 $529 \ldots \ldots \ldots \ldots \ldots \ldots$ SSSSSVGGGTASSAGGGSSASASSSGVYSTEMQY 562 800 LQLHSAASGGHPGGQKTSADVFTNLVSTYGGYHSSIDYHNAMTPPSSVSP 849 $563 \ldots \ldots \ldots \ldots$ PDTTTGNLYYNNNNHYYYDYDATVDVATSMIRPFSANS 600 850 RDSNQPGKAAPVLASNGGYDYAPDPLRGQYATSSGDVVPATLPLKPQASY 899

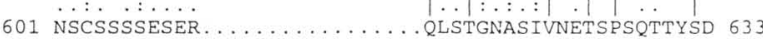
900 TATMHPSGSTTTEGGVTYSNLDQPQYFAPHSSFHLYHKGSPASGWYSTPS 949 634 LSHNF ELSYF SDNSSQQHQHQQQQQHLMEQQHLQYQYATW
Figure 2. Structure of the trh gene and protein. $(A)$ The genomic region of $1-e v e-1$ is shown. Exons are denoted by boxes; shaded boxes represent the coding region. The positions of insertion of P-element lines and the alternative splices (al) are shown. Vertical lines represent EcoRI sites. (B) Structure of the Trh protein. The bHLH domain is marked by a solid box, the two PAS repeats by a hatched box, and the transcription activation domain, rich in proline, glutamine, and serine residues $(\mathrm{P}, \mathrm{Q}, \mathrm{S})$ is marked by a shaded box. (NLS) Nuclear localization signal; $(a 1, a 2)$ alternative splice sites. The scheme includes the alternative exons, and the protein is drawn to scale. $(C)$ Trh is homologous to Sim. An alignment of the Trh protein (top line) with Sim demonstrates a high degree of homology. Identical residues are marked by vertical lines, and conservative changes by two dots. Protein domains are shown, and exon junctions for the four $5^{\prime}$ exons are marked by arrowheads.

on, expression in the migrating tracheal cells is also observed (data not shown).

An antibody raised against a region containing the PAS spacer and PAS B domains of the protein stains the nuclei of all tracheal cells (Fig. 1D). In addition, staining in the salivary gland ducts, and weak staining in the salivary glands is observed (Fig. 1E). A third tissue in which staining is detected represents the cell clusters in segment $\mathrm{A} 8$ that give rise to the posterior spiracles (Fig. 1F). Expression in the posterior spiracles initiates after the onset of expression in the tracheal placodes and persists until the posterior spiracles fuse with the tracheal dorsal trunk. The antibody specifically detects a protein of $\sim 150 \mathrm{kD}$ on Western blots of embryonic extracts (data not shown). Although this size is larger than the expected molecular mass of the protein, similar discrepancies were observed for other bHLH-PAS proteins (Wang et al. 1995).

\section{Trh is necessary for tracheal cell fate determination}

The expression of trh throughout tracheal development and its homology to Sim, which was shown to be the inducer of midline cell fates, raised the prospect that it would be necessary for tracheal cell fate determination. To examine this possibility, a dominant-negative construct was generated, similar to the one that has been used for Sim (Franks and Crews 1994): The transcription activation domain was deleted, but all other parts of the protein including the nuclear localization signal were retained. A tag sequence at the carboxy-terminal tail was added to allow detection of the induced construct. The gene was placed under the regulation of the Gal4 UAS sequence (Brand and Perrimon 1993), and transgenic lines were generated. To express the dominant-negative construct at high levels and at the desired time windows, an hsp70-gal4 inducer line was used.

Embryos were heat-shocked at $2.5 \mathrm{hr}$ after egg lay (AEL) and scored at stage $14-15$ by utilizing an antibody specific to the tracheal lumen. Phenotypes could be observed only when two copies of the dominant-negative construct were present. Wild-type embryos show the stereotyped branching pattern of the tracheal tree, whereas 
no lumen staining is observed in the induced embryos (cf. Fig. 3A and B). Invaginations of a few tracheal cells that express a small patch of lumen material are occasionally detected. The observed effects are specific, as induction of Gal4 expression in embryos that contain one or no copies of the dominant-negative construct does not result in a detectable phenotype (data not shown).

The dominant-negative construct also allowed us to examine to determine whether the gene is essential only for the onset of tracheal differentiation or for subsequent phases as well. Induction of the construct later in development, at $4 \mathrm{hr}$ AEL, does not perturb the formation of the tracheal pits. However, examination of tracheal structures at stage 15 demonstrates that more specific processes failed to take place: Although the tracheal cells form tubular structures and secrete the lumen antigens, the cells of the dorsal trunk in each segment fail to fuse with their neighbors in the adjacent segments and to form a continuous dorsal trunk (Fig. 3C). The migra-

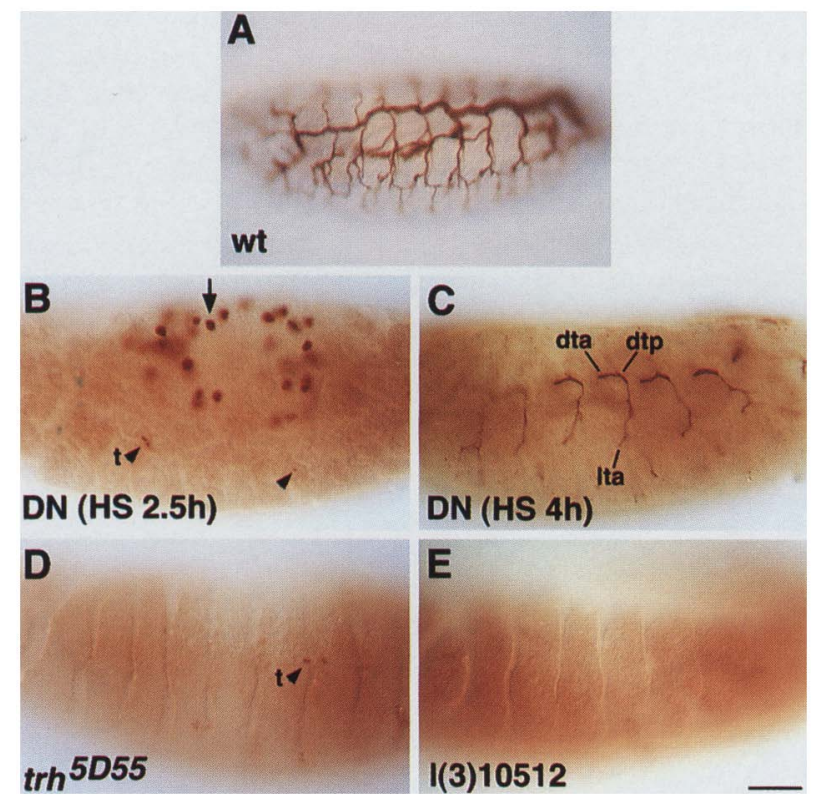

Figure 3. $t r h$ is necessary for tracheal fate determination. $|A|$ Wild-type embryo (stage 15) stained with the tracheal lumenspecific antibody 55. (B) Embryos carrying two copies of the dominant-negative construct and $h s p 70-g a l 4$. Following heat shocks at 2.5 and $8 \mathrm{hr}$, only small tracheal patches $(\mathrm{t})$ expressing the lumen antigen can be observed at stage 15. Staining of the tag is detected in these embryos, e.g., in the amnioserosal nuclei (arrow). (C) When similar embryos as in $B$ are heat-shocked at 4 and $8 \mathrm{hr}$, tracheal structures develop (visualized by antibody 55 staining at stage 15). However, the anterior dorsal trunk cells (dta) do not fuse with the posterior dorsal trunk cells (dtp) in the adjacent segment. Similarly, the anterior lateral trunk cells (lta) do not fuse with the posterior lateral trunk cells of the adjacent segment. $(D)$ Homozygous $t r h^{5 D 55}$ embryos stained with antibody 55 show only small patches of tracheal cells $(t)$ at stage 15 . (E) Homozygous 1(3)10512 embryos stained with anti-Trh antibodies at stage 12 show neither invagination of tracheal placodes nor staining. Scale bar, $50 \mu \mathrm{m}(A) ; 30 \mu \mathrm{m}(B-E, H)$. tion of other branches (e.g., the dorsal branch) is also stalled.

\section{1-eve-1 is inserted next to the trh gene}

The 1-eve-1 insertion site was mapped by in situ hybridization to band $61 \mathrm{~B} 3 / \mathrm{Cl}$, utilizing the $7-\mathrm{kb}$ genomic fragment as a probe (data not shown). This chromosomal position is in close proximity to that of the trh locus (Jürgens et al. 1984). Furthermore, trh mutant embryos display a phenotype that is remarkably similar to the one identified in embryos in which the dominant-negative construct was induced. In trh ${ }^{5 D 55}$ embryos, tracheal structures are not formed. Only small invaginations can occasionally be detected (Fig. 3D; Younossi-Hartenstein and Hartenstein 1993). Moreover, two other tissues in which the expression of 1-eve-1 was detected are affected in trh embryos: Salivary gland ducts do not develop (Younossi-Hartenstein and Hartenstein 1993), and the filzkörper produced by the posterior spiracles is defective (Jürgens et al. 1984).

Because the 1-eve-1 insertion does not produce a detectable phenotype and the element is inserted $10 \mathrm{~kb}$ upstream to the $5^{\prime}$ end of the trh transcript, additional enhancer trap elements in the $61 \mathrm{C}$ region were tested for allelism to trh. One of them, $1(3) 10512$, fails to complement $t r h^{5 D 55}$ and displays a more severe tracheal phenotype with no traces of lumen staining (data not shown). Precise excisions of the 1(3)10512 element are viable over the $t r h^{5 D 55}$ chromosome (D. Andrew, pers. comm.). PCR-based nucleotide analysis shows that the element is inserted in the $5^{\prime}$-noncoding part of the first exon $1674 \mathrm{bp}$ upstream to the designated initiator ATG) (Fig. 2A). We therefore conclude that the bHLH-PAS protein is encoded by trh. The availability of the 1(3)10512 trh allele, which we expect to be a null, was used to examine the mutant phenotype in greater detail. In homozygous 1(3)10512 embryos, no expression of the Trh protein can be detected in the tracheal placodes, and no invagination of these cells is observed by Nomarski optics (Fig. 3E).

\section{Ectopic Trh induces tracheal cell fates}

Having established that Trh is a transcription factor necessary for determination of tracheal fate, it was of interest to examine whether the expression of the gene is also sufficient for the induction of tracheal fate at ectopic locations. Fly strains containing the cDNA encoding the full-length Trh protein under Gal4/UAS regulation were generated. The consequences of ectopic expression by different inducers were examined.

Early ubiquitous expression, driven by the hsp70-gal4 construct, resulted in the formation of extra tracheal pits, as monitored by the expression of the 1-eve-1 lacZ marker and the invagination of the cells. Normally, the tracheal pits are formed in parasegments T2-A8. Following ectopic trh expression, two additional, smaller pits are observed in the parasegments anterior to $\mathrm{T} 2$. The formation of an additional posterior tracheal pit in A8 is also detected (Fig. 4A,B). The cells at the ectopic pits 

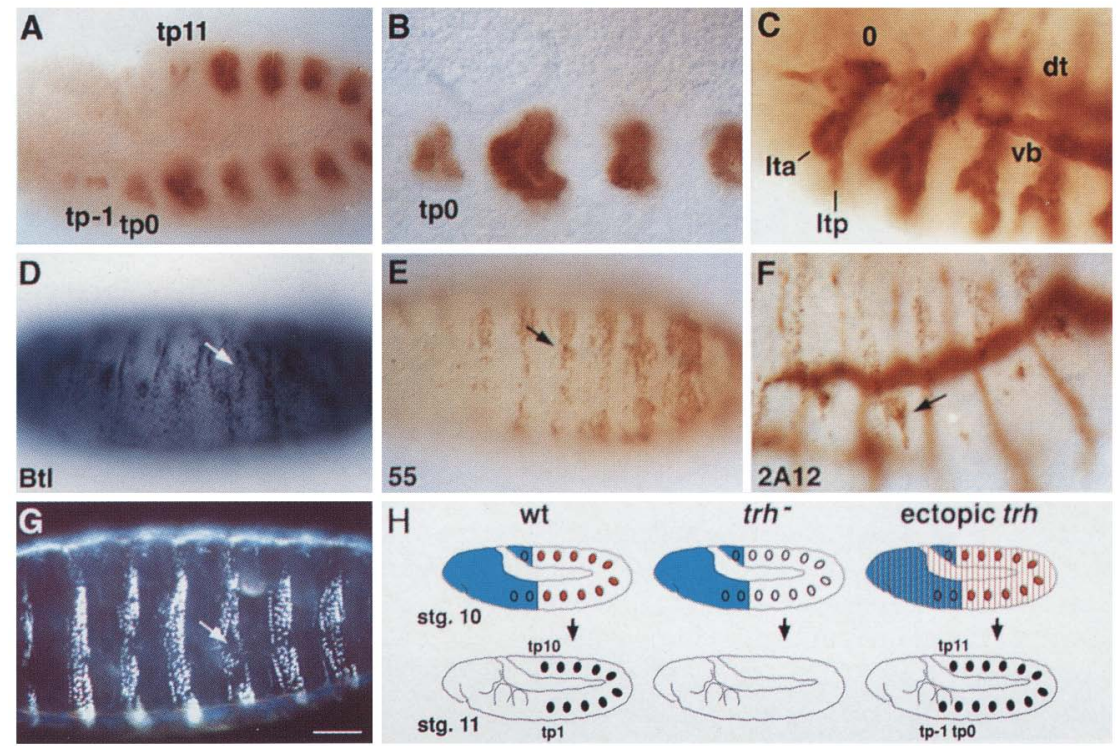

Figure 4. Induction of ectopic tracheal fates by Trh. (A) Embryos carrying the 1-eve-1, UAS-trh3 and hsp70-gal4 chromosomes, were heat-shocked at $2.5 \mathrm{hr}$ AEL and stained with anti- $\beta$-Gal antibodies at stage 12. In addition to the 10 pits expressing 1-eve-1, 2 additional anterior pits (tp0 and tp-1) and one extra posterior pit (tp11) are detected. (B) Same experiment as in $A$, showing an embryo carrying the UAS-trh 3' construct. $(C)$ When the same embryos as in $A$ were stained at stage 14 , the extra pits invaginate and generate typical anterior and posterior lateral trunk structures (Ita and ltp, respectively). The cells originating from tp0 (marked by 0) are shown. (dt) Dorsal trunk; $(v b)$ visceral branch. $(D)$ Embryos carrying the UAS-trh 3 construct, and the H82, hsp70-gal4 chromosome, were heatshocked at $2.5 \mathrm{hr}$ and stained with anti- $\beta$ $\mathrm{Gal}$ antibodies at stage 14. Ectopic ectodermal patches expressing the breathless marker can be observed (arrow). (E) Embryos carrying the UAS-trh $3^{\prime}$ construct on the third chromosome and ptc-gal4 on the second chromosome show at stage 14 ectodermal stripes expressing the tracheal lumen antigen as visualized by staining with antibody $55 .(F)$ Embryos carrying the UAS-trh3 construct and hsp 70-gal4, were heat-shocked at $2.5 \mathrm{hr}$ AEL and stained with anti-lumen antibody $2 \mathrm{Al} 2$ at stage 14 . Ectopic ectodermal patches displaying the marker in exocytotic vesicles can be observed (arrow). $(G)$ Cuticle preparation of an embryo in which the UAS-trh3 construct was induced by 69B-gal4. Patches missing cuticle structures are most evident in the region of the denticle bands (arrow). (H) A model for the early effects of ectopic trh expression. In wild-type embryos, the positions of the tracheal placodes are determined by cues from the anterior-posterior and dorsoventral axes in all segments (bold circles at stage 10). However, only in the 10 trunk segments, is the expression of $t r h$ (red) and the formation of tracheal pits (solid black circles at stage 11) induced. This may result either from general repression of $t r h$ transcription in the head and tail regions (blue) or broad enhancement of trh transcription in the trunk (white). In trh mutant embryos the anterior-posterior and dorsoventral cues are present, but trh is not expressed or is expressed as a nonfunctional protein. Therefore, no tracheal pits develop. Following ectopic expression of trh in embryos (red stripes), the induction of endogenous trh expression in the head and tail at the appropriate positions is reinforced, and additional tracheal pits develop. Scale bar, $40 \mu \mathrm{m}(A, D, E, G) ; 20 \mu \mathrm{m}(B, C, F)$.

invaginate and migrate to form anterior and posterior lateral trunk branches (Fig. 4C).

Except for the extra pits, no ectopic tracheal cells appear in other locations on the ectoderm up to stage 13, as assayed by the expression of the 1-eve-1 lac Z marker. However, following induction by hsp70-gal4, 69B-gal4 or ptc-gal4, alterations in the fate of the ectodermal cells are observed later in development (stages 14-15). Cuticle preparations displayed holes of various sizes in different parts of the embryo (Fig. 4G). Induction of the breathless gene (Fig. 4D), as well as trh itself (Fig. 5C) is also observed in these patches. Finally, the lumen antigens that are normally secreted by the tracheal cells into the tracheal tubes are also produced ectopically. In the case of one lumen marker (55), the lumen antigens are secreted to the extracellular space between the cells, because the ectopic tracheal patches do not invaginate to form tubular structures (Fig. 4E). Another lumen marker (2A12) that is normally detected also in exocytotic vesicles within the tracheal cells can be identified on the ectodermal patches in similar vesicles (Fig. 4F).

\section{Biphasic regulation of trh expression}

The initial determination of the sites of trh expression, which will define the position and number of tracheal placodes, is likely to be dictated by cues from both anterior-posterior and dorsoventral axes of the embryonic ectoderm. The expression pattern of $t r h$ can be altered in mutant embryos in which either one of the axes is abnormal. In wingless $(w g)$ mutant embryos, the tracheal pits appear to be almost normal up to stage 12. However, at stage 13 , the cells between the pits, normally expressing $w g$, assume a tracheal fate and express a variety of tracheal markers including trh (Fig. 5A). The dorsoventral boundaries of trh expression in these embryos are retained. To alter the polarity of the dorsoventral axis, a single copy of the $d p p$ gene was removed. In haplo-insufficient $d p p$ embryos the tracheal pits appear more elongated, whereas the anterior-posterior boundaries of trh expression are normal (Fig. 5B).

The initial external cues guiding trh expression are transient. To maintain expression of the gene throughout tracheal development, the capacity of Trachealess to regulate its own transcription (directly or indirectly) has to be postulated. This autoregulation was identified following the ectopic expression of $t r h$, which induced expression of the 1-eve-1 enhancer trap in the additional tracheal pits and branches (Fig. 4A-C) and in patches of cells on the ventral ectoderm (Fig. 5C). 
Figure 5. Biphasic regulation of trh expression. In the initial phase, the expression of trh is driven by cues from the anterior-posterior and dorsoventral axes. $(A)$ In wg mutant embryos carrying 1-eve-1, expression of the marker at stage 13 expands to the interpit region but retains the normal dorsoventral boundaries. (B) In embryos carrying 1-eve-1, which are haploinsufficient for $d p p$, expression of the marker spreads in the dorsoventral direction but retains the normal anterior-posterior position. $|C|$ Trh can autoregulate its own transcription. In embryos carrying the UAS-trhX, l-eve-1 and 69Bgal4 chromosomes, expression of the
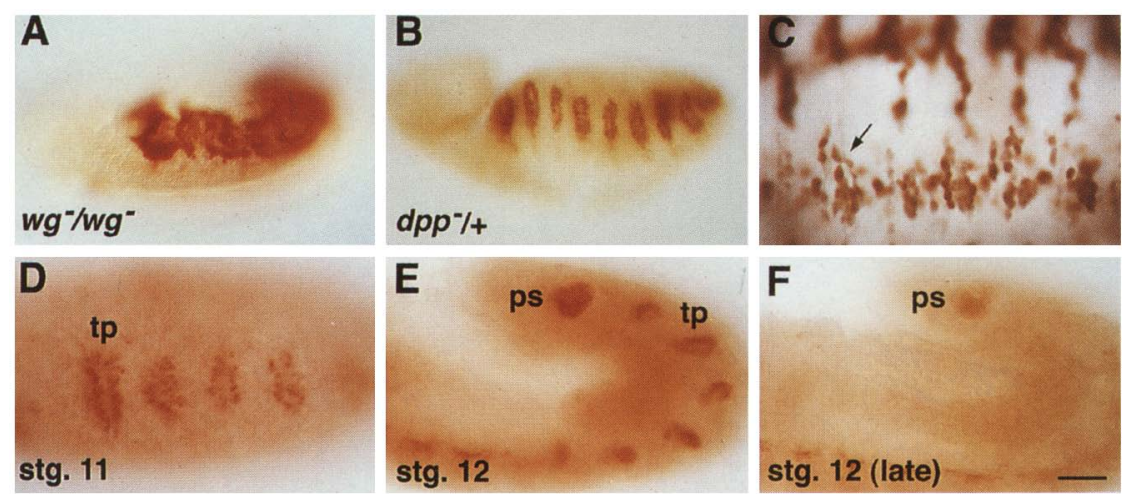

F

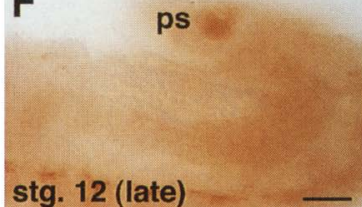
marker is detected not only in the tracheal cells but also in the ectopic ventral ectodermal cell patches (arrow). The biphasic regulation of $t r h$ transcription was also revealed when monitoring the expression of $t r h$ by anti-Trh antibodies in $t r h^{5 D 55}$ homozygous embryos. At stage $11(D)$, tracheal pits (tp) expressing the protein are observed. At stage $12\{E\}$, the posterior spiracle cells (ps) also express the protein. By late stage $12(F)$, only residual expression of the protein in the posterior spiracles is detected, whereas no protein is seen in the tracheal pits. Scale bar, $50 \mu \mathrm{m}\langle A, B| ; 30 \mu \mathrm{m}\langle C-F\rangle$.

The expression of the Trh protein in $t r h^{5 D 55}$ mutant embryos is also consistent with a biphasic mode of transcriptional regulation. This allele is an ethylmethane sulfonate (EMS)-induced hypomorph. In the mutant embryos the formation of tracheal pits is not blocked, and the tracheal cells express the Trh protein until stage 12 (Fig. 5D,E). However, the protein encoded by $t r h^{5 D 55}$ appears to be defective in autoregulation, and the Trh protein is no longer detected at late stage 12 (Fig. $5 \mathrm{~F}$ ), reflecting the transition from external induction to autoregulation of trh expression and the half-life of the protein.

\section{Discussion}

This work describes the identification of the trh gene, encoding a bHLH-PAS transcription factor, as the key regulator of tracheal fate determination. It extends the paradigm of bHLH proteins playing primary roles in the determination of tissue identity in a wide variety of biological systems and raises specific questions regarding the detailed mechanism of tracheal differentiation.

\section{Trh is a regulator of tracheal fates}

The trh mutant phenotype which is also observed following the early expression of the dominant-negative construct demonstrates that Trh is essential for the establishment of tracheal cell fate. In the absence of a functional protein, the tracheal placodes are not defined and invagination of the cells to form the tracheal pits does not take place. Ectopic expression of Trh has demonstrated its potency to induce extra tracheal pits. In addition, ectodermal patches expressing a variety of tracheal markers including trh itself, breathless and tracheal lumen antigens has been detected. It is not clear however, that Trh is sufficient to induce invagination of the tracheal cells. The ectopic patches of ectodermal cells that express tracheal markers do not invaginate to form pit- like structures. Therefore, another gene or set of genes that may be specifically expressed in the placodes at the appropriate time could function in conjunction with $\mathrm{Trh}$ to bring about the invagination of the cells. The localized and transient expression of a gene, which may have a function similar to the folded gastrulation gene that was shown to facilitate the invagination of the mesodermal and posterior midgut cells (Costa et al. 1994), could be required to induce the invagination at the tracheal pits.

Following ectopic expression of Trh, additional tracheal pits were generated at the correct position in segments that normally do not form pits. Although the expression of Trh was ubiquitously induced by the $h s p 70$ promoter, the expression of 1-eve-1 and the formation of ectopic pits was observed only in the correct coordinates with respect to the anterior-posterior and dorsoventral axes. The ability of Trh to induce its own expression and the consequent formation of tracheal pits at the early stages may only be manifested at positions where Trh synergizes with other transcriptional activators present in the tracheal placode cells. These additional transcriptional activators could represent the cues from the anterior-posterior and dorsoventral axes, defining the tracheal placodes.

Because tracheal pits could be induced in 13-14 segments at the correct positions, why are tracheal pits normally formed only in the 10 trunk segments? It is possible that the transcription of trh is also stimulated by trunk-specific genes such as teashirt (Röder et al. 1992; de Zulueta et al. 1994), or repressed in the head and tail regions by genes like spalt (Kuhnlein et al. 1994). The excess amount of Trh provided by the ectopic expression may be sufficient to substitute for positive general trunk activators or to overcome the inhibition by head and tail transcriptional repressors (see model in Fig. 4H). The ability to generate additional tracheal pits corroborates a hypothesis that in the primordial segmented organism, where the distinction of head and tail segments was less pronounced, all segments had the capacity to produce 
tracheal precursors. In some insects transient tracheal pits appear in 14 segments (Edwards 1953).

As a consequence of autoregulation, expression of trh is maintained throughout tracheal development. Defects in tracheal structure were observed following later induction of the dominant-negative Trh construct. These abnormalities may arise from the absence of general tracheal proteins that are normally induced by Trh, for example, cell adhesion molecules. Alternatively, Trh may also be required for distinct events of cell fate specification within the population of tracheal cells. Although all tracheal cells in the placode initially appear identical and express the same general markers, specification within the population of these cells is observed as the process of tracheal migration proceeds. This specialization is probably induced by cues from the ectodermal cells, as well as by cross talk between the tracheal cells. The simultaneous requirement for general activation by Trh, as well as by specific activators within a given subpopulation of tracheal cells, may allow a more stringent selection of target genes. Cooperative binding of transcription factors from the bHLH family and of other types has been reported for several target genes, for example, snail (Ip et al. 19921.

\section{Trh is a bHLH-PAS protein}

The predicted sequence of the Trh protein demonstrates that it is a bHLH-PAS protein, containing also a nuclear localization signal and a transcription activation domain, with the highest degree of homology to Sim. Although a large number of bHLH proteins have been described to date (Jan and Jan 1993; Kadesch 1993), the presence of the PAS motif is rare and has been observed previously in five other eukaryotic proteins: Per (Jackson et al. 1986; Yu et al. 1987; Crews et al. 1988); AhR (Burbach et al. 1992; Ema et al. 1992); Arnt (Hoffman et al. 1991); HIF (Wang et al. 1995); and Sim (Crews et al. 1988; Nambu et al. 1991); hence, the name PAS. This domain ( $\sim 50$ amino acids) is duplicated with a typical spacing. The homology between the PAS A or PAS B domains of Trh and Sim is higher than that between PAS A and PAS $B$ repeats within each protein. It is therefore reasonable to speculate that gene duplication events that gave rise to the various PAS-containing proteins were preceded by a duplication of the PAS motif within the ancestral gene. In this context, it is interesting to note that PAS A and B motifs have also been identified in the bacterial protein KinA (Perego et al. 1989; Wang et al. 1995). The PAS domains appear to be important for protein-protein interactions (Zuoshi et al. 1993; Lindebro et al. 1995). The AhR and Arnt proteins form a functional heterodimer in liver cells, which induces the transcription of detoxifying enzymes (Reyes et al. 1992; Matsushita et al. 1993; Whitelaw et al. 1993; Lindebro et al. 1995; Wang et al. 1995).

The examples of the AhR/Arnt and HIF/Arnt pairs suggest that heterodimer formation is a general property of the PAS proteins. This notion is supported by the asymmetrical $\mathrm{E}$ box-like DNA-binding site that has been identified for Sim. It was suggested that one part is recognized by Sim, which has an atypical basic domain (like $\mathrm{AhR}$ ), whereas the other half representing a classic E box, is recognized by an Arnt-related protein (Wharton et al. 1994). It is possibile that Trh also forms a heterodimer with another bHLH-PAS protein, representing an Arntrelated partner. Trh may also associate with more than one partner in the course of normal development. The ability to obtain ectopic tracheal fates on the ectoderm following ubiquitous expression of Trh suggests that this putative partner is widely expressed. However, we cannot exclude the possibility that the ectopic Trh protein may form a functional heterodimer with a protein that is not its normal partner.

It is interesting to note that overexpression of the dominant-negative Trh construct, which abolished the development of normal tracheal structures, was still capable of inducing the formation of ectopic ectodermal patches expressing tracheal markers, similar to the fulllength construct (data not shown). Heterodimers of dominant-negative Trh with its putative partner should still contain a single transcription activation domain, which may give rise to activity levels that are sufficient for the induction of ectopic patches but not for the formation of normal tracheal structures.

In spite of the structural homology between Trh and Sim, they appear to activate different target genes. Ectopic expression of Sim resulted in increase of midline fate, as monitored by the expression of the breathless gene, whereas no effect on tracheal fate was observed (data not shown). In addition, overexpression of Trh did not result in expansion or reduction of the midline cells (data not shown). Finally, the dominant-negative Trh protein, which eliminated the formation of tracheal placodes, did not affect the midline (data not shown). Trh and Sim may form heterodimers with different partners, which may influence the selection of target genes. Differences in the basic region (9 of 12 residues are identical) may also contribute to the induction of distinct target genes.

The human HIF bHLH-PAS protein that is induced under hypoxic conditions in liver cells has been identified recently as a partner of Arnt and is responsible for the induction of erythropoietin expression (Wang et al. 1995). All 12 residues in the basic domain of HIF are identical to the Trh sequence. This complete identity in the DNA-binding domain raises the provocative possibility that the targets of a human hypoxia-inducible factor and the Drosophila tracheal fate regulator have been conserved. The recent identification of a human Sim homolog, in which $11 / 12$ amino acids in the basic region are identical (Chen et al. 1995), may suggest a similar paradigm for the Sim targets.

\section{Trh is required for tube fate determination} in several tissues

The expression of Trh and the phenotypes of mutations in the gene involve two other tissues in addition to the trachea: the posterior spiracles and the salivary gland 
ducts. Both of these tissues have many features in common with the trachea. They invaginate from placodes on the ectoderm to form tubular structures and make stereotypic connections with the trachea or the salivary glands, respectively. The cells form a polarized layer (secreting different components by the basal or apical membranes), maintain tight junctions within the tissue, and fuse with cells from adjacent segments to generate a continuous tubular structure. It is thus tempting to suggest that genes responsible for general features of tubular structures are induced by Trh in all three tissues.

There are, however, differences between the tissues in which Trh is expressed, reflected in morphology and patterns of gene expression. For example, breathless is expressed in the trachea and salivary duct but not in the posterior spiracles (Klämbt et al. 1992), whereas the lumen antigens detected by antibodies $2 \mathrm{~A} 12$ and 55 appear to be predominantly tracheal specific. Therefore, in conjunction with the general role of Trh, more specific and localized cues must dictate the identity of the different tissues in which $\operatorname{Trh}$ is required. The markers we have tested demonstrate that Trh can induce the formation of ectopic tracheal cells. It would be interesting to determine whether the ectopic expression of specific salivary duct or posterior spiracle markers can be induced similarly. Alternative splicing forms of Trh may dictate different fates, by associating with different partner molecules. It is tempting to speculate that in vertebrate organisms, the formation of branched tubular structures, including the lung and circulatory system, may also rely on induction by similar proteins.

\section{Materials and methods}

Library screens, sequencing, and constructs

The P-element vector used to generate the l-eve-1 line does not contain plasmid sequences between the terminal repeats. Therefore, the genomic sequences flanking the integration site had to be cloned by construction of a library. 1-eve-1 genomic DNA was digested with EcoRI and probed with the $0.55-\mathrm{kb}$ HindIII-EcoRI 5' P-element terminal fragment (prepared from Carnegie-20). A 1.1-kb fragment was detected and cloned in the Lambda Zap II vector (Stratagene), using the Gigapack II Plus packaging extract (Stratagene). The cloned fragment detected an EcoRI fragment of $1.2-\mathrm{kb}$ in a genomic Southern blot of wildtype flies. It was used to screen a genomic partial EcoRI library in Charon 4A [obtained from N. Davidson, California Institute of Technology (Cal Tech), Pasadena], and isolate overlapping clones. The relevant genomic fragment containing the transcript was identified by whole-mount in situ hybridization to embryos, probed with the different genomic EcoRI fragments. It was used to screen a 9- to 12 -hr embryonic cDNA library in $\lambda$ gt11 (obtained from K. Zinn, Cal Tech). The isolated cDNA clones were sequenced by synthetic oligonucleotides with the Applied biosystems automatic sequencer. The GenBank accession number is U33427. The mapping of genomic EcoRI fragments was achieved by restriction mapping, PCR analysis, and sequence across the EcoRI sites. Positions of exons were determined by sequence of genomic fragments and PCR analysis. The insertion site of the 1/3)10512 P element was determined by PCR analysis using one oligonucleotide from the 31-bp P-element inverted repeat, and the other oligonucleotide from the flanking genomic sequence. To identify the precise insertion site, the fragment generated by PCR was sequenced.

To generate the Trh overexpressing construct (pUAS-trh), the 4.2-kb cDNA clone containing the entire coding region was inserted into the EcoRI site of the pUAST vector (Brand and Perrimon 1993). To generate the dominant-negative Trh construct, pUAS-trh was digested with EagI (to remove the coding sequence downstream to the nuclear localization signal, from residue 673) and $\mathrm{XbaI}$. An EagI-XbaI oligonucleotide adapter encoding the $\mathrm{T} 7 \mathrm{tag}$ (Novagene) followed by a termination codon was inserted to generate the pUAS-trh DN construct.

\section{In situ hybridization and antibody staining}

Standard protocols were used for whole-mount dioxygenin RNA in situ hybridization with genomic or cDNA probes (Ashburner 1989; Tautz and Pfeifle 1989), using the Boehringer Mannheim kit. To generate anti-Trh antibodies, a 1-kb XhoI-EcoRI fragment from a shorter trh cDNA clone, encoding the PAS spacer PAS B and the residues up to the nuclear localization signal (residues 243-619), was inserted into pRSET B vector (Invitrogen). The induced protein was purified on a NINTA column and injected into mice. Polyclonal antibodies obtained were absorbed on 0- to 2-hr embryos. Standard protocols were used for immunohistochemistry (Ashburner 1989) (for $\mathrm{NiCl}_{2}-$ $\mathrm{CoCl}_{2}$ staining of Fig. 4D, see Raz and Shilo 1993) and Western blotting with the ECL kit (Amersham). Additional antibodies used for immunohistochemistry include: guinea pig anti-tracheal lumen antibody 55 (Reichman-Fried et al. 1994), anti-tracheal lumen mAb $2 \mathrm{~A} 12$ (from N. Patel and C.S. Goodman, University of California, Berkeley), rabbit anti- $\beta$-Gal (Cappel), and monoclonal anti-T7 tag (Novagene). HRP-conjugated secondary antibodies (Jackson) were used. For the 2A12 antibody, the Vectastain Elite kit was used.

For X-gal staining of trachea from third-instar larvae, trachea were fixed for $10 \mathrm{~min}$ in $2.5 \%$ glutaraldehide in PEM:PT 1:2 |for PEM, see Ashburner 1989; PT = PBS, 0.1\% Triton-X|, followed by washing in $\mathrm{PT}$ and incubation at $37^{\circ} \mathrm{C}$ in staining solution $\left[0.2 \% \mathrm{X}\right.$-gal in $5 \mathrm{~mm} \mathrm{~K}_{3} \mathrm{Fe}(\mathrm{CN})_{6}, 5 \mathrm{~mm} \mathrm{~K}_{4} \mathrm{Fe}(\mathrm{CN})_{6}$ in PBS $]$.

\section{Fly strains}

Standard methods were used to generate transgenic lines (Ashburner 1989|. Four lines carrying the pUAS-trh DN construct were obtained. Three lines were chosen for subsequent analysis; UAS-trh DN X, UAS-trh DN 2, and UAS-trh DN 3 (inserted on the $\mathrm{X}$, second, and third chromosome, respectively). Phenotypes were observed only in strains carrying one copy of UAS-trh DN $\mathrm{X}$ and one copy of UAS-trh DN 3 . Six lines carrying the pUAStrh construct were obtained. Three lines were chosen for subsequent analysis; UAS-trhX (inserted on the X chromosome), UAS-trh 3 and UAS-trh 3 ' (inserted on the third chromosome). To follow the effects on the expression of 1-eve-1, the two lines on the third chromosome were recombined to l-eve-1.

The following lines expressing Gal4 were used: 69B (obtained from A. Brand and N. Perrimon) is a homozygous insertion in the third chromosome (Brand and Perrimon 1993); it is initially expressed in the embryo at stage 10 in a segmented pattern and develops into a general ectodermal staining by stage 10-11. K25 (2Xsevhsp70-gal4) (obtained from E. Hafen, University of Zurich, Switzerland) is a homozygous insertion on the third chromosome of a $\mathrm{P}\left[\mathrm{ry}^{+}\right]$construct expressing Gal4 under the sev enhancer and $h s p 70$ promoter (hsp 70-gal4). ptc-gal4 is inserted on the second chromosome (provided by U. Hinz and J. CamposOrtega, Cologne University, Germany). To follow breathless expression, a recombinant chromosome containing the $\mathrm{H} 82$ en- 
hancer trap line (Klämbt et al. 1992) and K25 was used (Reichman-Fried and Shilo 1995). 1-eve-1 is a homozygous viable line (provided by N. Perrimon) containing the enhancer trap on the 3rd chromosome (Perrimon et al. 1991). $\operatorname{trh}^{5 D 55}$ was obtained from M. Krasnow (Stanford University, California), and the trh 1(3)10512 line was obtained from the Bloomington stock center. A third balancer chromosome containing an enhancer trap was used to identify the homozygous mutant embryos. A line containing copies of $h s p 70-\operatorname{sim}$ on the second and third chromosome was obtained from S. Crews (University of North Carolina, Chapel Hill). Flies containing the $w g^{C X 4}$ and $d p p^{61}$ alleles were also used. $d p p^{61} / C y O$ stock (obtained from $M$. Hoffmann, University of Wisconsin, Madison) was kept with the $d p p-7291$ P element on the third chromosome.

\section{Temperature shift protocols}

Embryos carrying the $h s p 70$-gal4 construct were subjected to temperature shift protocols. Heat shock treatments were carried out for $20 \mathrm{~min}$ at $37^{\circ} \mathrm{C}$ at the indicated time points. To detect the tagged trh $\mathrm{DN}$ protein, embryos were subjected to an additional heat shock, 2-3 hr before fixation. To obtain extra tracheal pits or branches in embryos carrying the UAS-trh construct, heat shock was carried out at $38-39^{\circ} \mathrm{C}$. In all cases, embryos were synchronized $\pm 0.5 \mathrm{hr}$.

\section{Acknowledgments}

We are grateful to $M$. Korman for help with 1-eve-1 cloning, $R$. Leiserowitz for producing Trh antibodies and help in generation of transgenic lines, O. Leitner for antibody production, E. Zeltser for identifying the trh alternative splicing patterns, and A. Salzberg for help in chromosomal in situs. We thank A. Brand, N. Perrimon, E. Hafen, U. Hinz, J. Campos-Ortega, M. Hoffmann, M. Krasnow, A. Spradling, N. Davidson, and K. Zinn for providing fly strains and reagents. We thank $D$. Andrew for sharing unpublished information, R. Schweitzer, M. ReichmanFried, M. Beiman, E. Zeltser, and M. Golembo for discussions, T. Volk and E. Schejter for critical reading of the manuscript, D. Strumpf, G. Pasca, and I. Haviv for advice, the photography and graphics departments of the Weizmann Institute for professional image processing, and the sequencing facility of the Weizmann Institute. The work was supported by grants from the National Institutes of Health, the US-Israel binational science foundation and the German-Israeli Foundation (to B.S.).

The publication costs of this article were defrayed in part by payment of page charges. This article must therefore be hereby marked "advertisement" in accordance with 18 USC section 1734 solely to indicate this fact.

\section{References}

Ashburner, M. 1989. Drosophila: A laboratory manual. Cold Spring Harbor Laboratory Press, Cold Spring Harbor, N.Y.

Brand, A.H. and N. Perrimon. 1993. Targeted gene expression as a means of altering cell fates and generating dominant phenotypes. Development 118: 401-415.

Burbach, K.M., A. Poland, and C.A. Bradfield. 1992. Cloning of the Ah-receptor cDNA reveals a distinctive ligand-activated transcription factor. Proc. Natl. Acad. Sci. 89: 8185-8189.

Campos-Ortega, J.A. and V. Hartenstein. 1985. The embryonic development of Drosophila melanogaster. Springer Verlag, Berlin/Heidelberg, Germany.

Chen, H., R. Chrast, C. Rossier, A. Gos, S.E. Antonarakis, J. Kudoh, A. Yamaki, Shindoh, H. Maeda, S. Minoshima, and
N. Shimizu. 1995. Single-minded and Down syndrome? Nature Genet. 10: 9-10.

Costa, M., E.T. Wilson, and E. Wieschaus. 1994. A putative cell signal encoded by the folded gastrulation gene coordinates cell shape changes during Drosophila gastrulation. Cell 76: $1075-1089$.

Crews, S.T., J.B. Thomas, and C.S. Goodman. 1988. The Drosophila single-minded gene encodes a nuclear protein with sequence similarity to the per gene product. Cell 52: 143-151.

Davis, R.L., H. Weintraub, and A.B. Lassar. 1987. Expression of a single transfected cDNA converts fibroblasts to myoblasts. Cell 51: 987-1000.

de Zulueta, P., E. Alexandre, B. Jacq, and S. Kerridge. 1994. Homeotic complex and teashirt genes cooperate to establish trunk segmental identities in Drosophila. Development 120: 2287-2296.

Edwards, G.A. 1953. The tracheal system (respiratory mechanisms|. In Insect physiology (ed. R.L. Beard, D. Bodenstein, J.B. Buck, L.E. Chadwick, M.F. Day, V.G. Dethier, G.A. Edwards, D. Gilmour, S.C. Munson, R.L. Patton, A.G. Richards, K.D. Roeder, T.C. Schneirla, W. Trager, and D.F. Waterhouse), pp. 55-65. John Wiley, New York, NY.

Ema, M., K. Sogawa, N. Watanabe, Y. Chujoh, N. Matsushita, O. Gotoh, Y. Funae, and Y. Fuji-Kuriyama. 1992. cDNA cloning and structure of mouse putative Ah receptor. Biochem. Biophys. Res. Commun. 184: 246-253.

Franks, R.G. and S.T. Crews. 1994. Transcriptional activation domains of the single-minded bHLH protein are required for CNS midline cell development. Mech. Dev. 45: 269-277.

Halder, G., P. Callaerts, and W.J. Gehring. 1995. Induction of ectopic eyes by targeted expression of the eyeless gene in Drosophila. Science 267: 1788-1792.

Hoffman, E.C., H. Reyes, F.-F. Chu, F. Sander, L.H. Conley, B.A. Brooks, and O. Hankinson. 1991. Cloning of a factor required for activity of the Ah (dioxin) receptor. Science 252: 954 958.

Ip, Y.T., R.E. Park, D. Kosman, K. Yazdanbakhsh, and M. Levine. 1992. dorsal-twist interactions establish snail expression in the presumptive mesoderm of the Drosophila embryo. Genes \& Dev. 6: 1518-1530.

Jackson, F.R., T.A. Bargiello, S.-H. Yun, and M.W. Young. 1986. Product of per locus of Drosophila shares homology with proteoglycans. Nature 320: 185-188.

Jan, Y.N. and L.Y. Jan. 1993. HLH proteins, fly neurogenesis, and vertebrate myogenesis. Cell 75: 827-830.

Jarman, A.P., Y. Grau, L.Y. Jan, and Y.N. Jan. 1993. atonal is a proneural gene that directs chordotonal organ formation in the Drosophila peripheral nervous system. Cell 73: 13071321.

Jarman, A.P., E.H. Grell, L. Ackerman, L.Y. Jan, and Y.N. Jan. 1994. atonal is the proneural gene for Drosophila photoreceptors. Nature 369: 398-400.

Jürgens, G.E. Wieschaus, C. Nüsslein-Volhard, and H. Kluding. 1984. Mutations affecting the pattern of the larval cuticle in Drosophila melanogaster. Roux's Arch. Dev. Biol. 193: 283295.

Kadesch, T. 1993. Consequences of heterodimeric interactions among helix-loop-helix proteins. Cell Growth Differ. 4: 4955.

Klämbt, C., L. Glazer, and B.Z. Shilo. 1992. breathless, a Drosophila FGF receptor homolog, is essential for migration of tracheal and specific midline glial cells. Genes \& Dev. 6: 1668-1678.

Kozak, M. 1987. An analysis of 5'-noncoding sequences from 699 vertebrate messenger RNAs. Nucleic Acids Res. 15: $8125-8148$. 
Kuhnlein, R.P., G. Frommer, M. Friedrich, M. Gonzalez-Gaitan, A. Weber, J.F. Wagner-Bernholz, W.J. Gehring, H. Jackle, and R. Schuh. 1994. spalt encodes an evolutionarily conserved zinc finger protein of novel structure which provides homeotic gene function in the head and tail region of the Drosophila embryo. EMBO I. 13: 168-179.

Lassar, A.B., B. Peterson, and H. Weintraub. 1986. Transfection of a DNA locus that mediates the conversion of $10 \mathrm{Tl} / 2$ fibroblasts to myoblasts. Cell 47: 649-656.

Lindebro, M.C., L. Poellinger, and M.L. Whitelaw. 1995. Protein-protein interaction via PAS domains: Role of the PAS domain in positive and negative regulation of the bHLH/ PAS dioxin receptor-Arnt transcription factor complex. EMBO 1. 14: 3528-3539.

Manning, G. and M.A. Krasnow. 1993. Development of the Drosophila tracheal system. In The development of Drosophila melanogaster (ed. M. Bate and A. Martinez-Arias), pp. 609-685. Cold Spring Harbor Laboratory Press, Cold Spring Harbor, N.Y.

Matsushita, N., K. Sogawa, M. Ema, A. Yoshida, and Y. FujiiKuriyama. 1993. A factor binding to the xenobiotic responsive element (XRE) of P-4501Al gene consists of at least two helix-loop-helix proteins, Ah receptor and Arnt. I. Biol. Chem. 268: 21002-21006.

Nambu, J.R., J.O. Lewis, J.K.A. Wharton, and S.T. Crews. 1991. The Drosophila single-minded gene encodes a helix-loophelix protein that acts as a master regulator of CNS midline development. Cell 67: 1157-1167.

Perego, M., S.P. Cole, D. Burbulys, K. Trach, and J.A. Hoch. 1989. Characterization of the gene for a protein kinase which phosphorylates the sporulation-regulatory proteins SpoOA and SpoOF of Bacillus subtilis. J. Bacteriol. 171: 6187-6196.

Perrimon, N., E. Noll, K. McCall, and A. Brand. 1991. Generating lineage-specific markers to study Drosophila development. Dev. Genet. 12: 238-252.

Reichman-Fried, M. and B.Z. Shilo. 1995. Breathless, a Drosophila FGF receptor homolog, is required for the onset of tracheal cell migration and tracheole formation. Mech. Dev. 52: 265-273.

Reichman-Fried, M., B. Dickson, E. Hafen, and B.Z. Shilo. 1994. Elucidation of the role of breathless, a Drosophila FGF receptor homolog, in tracheal cell migration. Genes \& Dev. 8: $428-439$.

Reyes, H., S. Reisz-Porszasz, and O. Hankinson. 1992. Identification of the Ah receptor nuclear translocator protein (Arnt) as a component of the DNA binding form of the Ah receptor. Science 256: 1193-1195.

Röder, L., C. Vola, and S. Kerridge. 1992. The role of the teashirt gene in trunk segmental identity in Drosophila. Development 115: 1017-1033.

Skeath, J.B. and S.B. Carroll. 1994. The achaete-scute complex: Generation of cellular pattern and fate within the Drosophila nervous system. FASEB I. 8: 714-721.

St Johnston, D. and C. Nüsslein-Volhard. 1992. The origin of pattern and polarity in the Drosophila embryo. Cell 68: 201219.

Tapscott, S.J., R.L. Davis, M.J. Thayer, P.F. Cheng, H. Weintraub, and A.B. Lassar. 1988. MyoDl: A nuclear phosphoprotein requiring a Myc homology region to convert fibroblasts to myoblasts. Science 242: 405-411.

Tautz, D. and C. Pfeifle. 1989. A non-radioactive in situ hybridization method for the localization of specific RNAs in Drosophila embryos reveals translational control of the segmentation gene hunchback. Chromosoma 98: 81-85.

Wang, G.L., B.-H. Jiang, E.A. Rue, and G.L. Semenza. 1995. Hypoxia-inducible factor 1 is a basic-helix-loop-helix-PAS het- erodimer regulated by cellular $\mathrm{O} 2$ tension. Proc. Nat1. Acad. Sci. 92: 5510-5514.

Wharton, K.A., R.G. Franks, Y. Kasai, and S.T. Crews. 1994. Control of CNS midline transcription by asymetric E-boxlike elements: Similarity to xenobiotic responsive regulation. Development 120: 3563-3569.

Whitelaw, M., I. Pongratz, A. Wilhelmsson, J.A. Gustafsson, and L. Poellinger. 1993. Ligand-dependent recruitment of the Arnt coregulator determines DNA recognition by the dioxin receptor. Mol. Cell. Biol. 13: 2504-2514.

Younossi-Hartenstein, A. and V. Hartenstein. 1993. The role of the tracheae and musculature during pathfinding of Drosophila embryonic sensory axons. Dev. Biol. 158: 430-447.

Yu, Q., A.C. Jacquier, Y. Citri, M. Hamblen, J.C. Hall, and M. Rosbash. 1987. Molecular mapping of point mutations in the period gene that stop or speed up biological clocks in Drosophila melanogaster. Proc. Natl. Acad. Sci. 84: 784-788.

Zuoshi, J.H., I. Edery, and M. Rosbash. 1993. PAS is a dimerization domain common to Drosophila Period and several transcription factors. Nature 364: 259-262. 


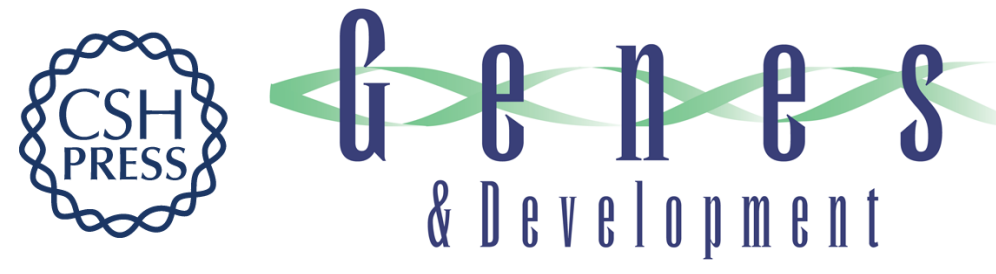

\section{trachealess encodes a bHLH-PAS protein that is an inducer of tracheal cell fates in Drosophila.}

R Wilk, I Weizman and B Z Shilo

Genes Dev. 1996, 10:

Access the most recent version at doi:10.1101/gad.10.1.93

References This article cites 41 articles, 17 of which can be accessed free at:

http://genesdev.cshlp.org/content/10/1/93.full.html\#ref-list-1

License

Email Alerting

Service

Receive free email alerts when new articles cite this article - sign up in the box at the top right corner of the article or click here.

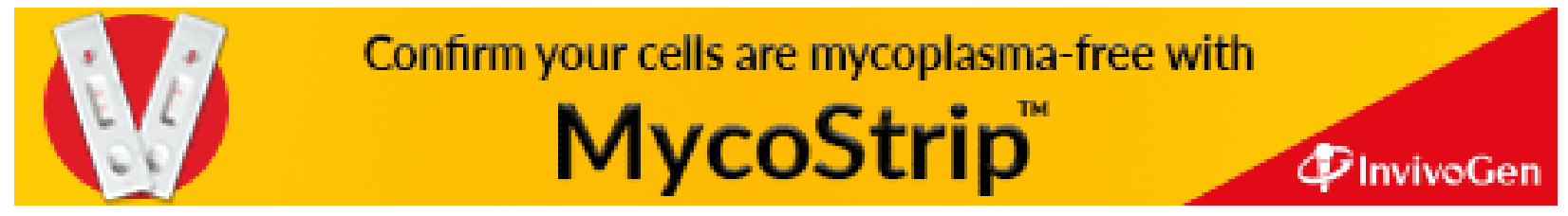

